\title{
REVIEW
}

\section{Iron deficiency in pulmonary arterial hypertension: a potential therapeutic target}

\author{
C.J. Rhodes*, J. Wharton*, L. Howard\#, J.S.R. Gibbs", \\ A. Vonk-Noordegraaf and M.R. Wilkins*
}

ABSTRACT: Iron deficiency is known to be common and detrimental in chronic left heart failure, where parenteral iron treatment has been shown to improve exercise capacity, New York Heart Association functional class and patient wellbeing. There is now increasing interest in the role of iron in the natural history of pulmonary arterial hypertension (PAH). Iron availability influences the pulmonary vasoconstrictor response to hypoxia and accumulating evidence indicates that iron deficiency is prevalent in idiopathic and heritable forms of $\mathrm{PAH}$, iron status being related to exercise capacity, symptoms and poorer survival in patients with idiopathic PAH (IPAH). Potential mechanisms behind iron deficiency in IPAH include inhibition of dietary iron uptake by the master iron regulator hepcidin. High hepcidin levels underlie the anaemia of chronic disease. Possible stimuli of the observed high levels of hepcidin in IPAH include dysfunctional bone morphogenetic protein receptor type II signalling and inflammation. Iron status may influence outcomes through modulation of the pulmonary circulation as well as myocardial and skeletal muscle function. Two parallel studies, from our centre (Hammersmith Hospital, London, UK) and others in the UK and Amsterdam (the Netherlands), investigating the safety and potential benefit of iron supplementation in patients with $\mathrm{PAH}$ are currently under way.

KEYWORDS: Heart failure, hypoxia, iron, pulmonary arterial hypertension, pulmonary vascular resistance, pulmonary vasculature

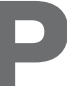

ulmonary arterial hypertension (PAH) is a heterogeneous condition that is characterised by a sustained increase in pulmonary artery pressure $(>25 \mathrm{mmHg})$ and normal pulmonary capillary wedge pressure $(<15 \mathrm{mmHg})$ with a normal or reduced cardiac output [1]. PAH can be idiopathic (IPAH), inherited or associated with other conditions, such as congenital heart disease (in particular, systemic-to-pulmonary shunts), connective tissue disease and chronic haemolytic anaemias, such as sickle cell disease [2]. It is a progressive vascular disease that leads to increased pulmonary vascular resistance, right ventricular failure and premature death. Recent data suggest that iron deficiency is also prevalent in IPAH [3-5], and may be related to morbidity and mortality [3,5]. Here, we discuss the potential importance of iron in the regulation of pulmonary vascular tone, heart failure and prognosis in pulmonary hypertension, as well as the potential mechanisms by which it might be dysregulated, and affect symptoms and survival in IPAH.

\section{IRON AND THE PULMONARY VASCULAR RESPONSE TO HYPOXIA}

Several human physiology studies indicate that iron availability influences pulmonary vascular homeostasis, in particular the pulmonary vasoconstrictor response to hypoxia. It has been proposed that iron deficiency mimics the pulmonary effects of hypoxia through the stabilisation of hypoxia-inducible factor (HIF), which is primarily regulated by specific prolyl hydroxylase-domain enzymes (PHDs) and degradation via the von Hippel-Lindau tumour suppressor protein $[6,7]$. Thus, the dependency of PHD activity on iron and oxygen is thought to account for regulation of the HIF pathway by both cellular oxygen and iron statuses. Intravenous infusion of the iron chelator desferrioxamine increased basal pulmonary artery systolic pressure in healthy volunteers, as assessed using Doppler echocardiography to measure the maximal transtricuspid pressure difference [8]. Although the increase was relatively modest $(\sim 25 \%)$ compared with that caused by hypoxia, the time course was similar and the magnitude of
AFFILIATIONS

${ }^{*}$ Centre for Pharmacology and Therapeutics, and ${ }^{\text {\#}}$ National Pulmonary Hypertension Service, Hammersmith Hospital, London, UK. -Dept of Pulmonology, VU University Medical Center, Amsterdam, The Netherlands.

CORRESPONDENCE

M.R. Wilkins

Centre for Pharmacology and

Therapeutics

Dept of Medicine

Hammersmith Hospital

Du Cane Road

London W12 0NN

UK

E-mail: m.wilkins@imperial.ac.uk

Received:

Feb 282011

Accepted after revision:

March 212011

First published online:

April 082011 
individual responses to hypoxia or iron chelation correlated strongly, suggesting that hypoxia might induce pulmonary hypertension, at least in part, via an iron-dependent mechanism.

Subsequently, it has been reported that an infusion of iron prevented the increased acute hypoxic pulmonary vasoconstrictive response normally induced by pre-exposure to hypoxia ( $\sim 10 \%$ oxygen) for $8 \mathrm{~h}$, whereas infusion of desferrioxamine exacerbated hypoxic pulmonary vasoreactivity [9]. Similarly, iron infusion attenuated the pulmonary hypertensive response to hypoxia in healthy volunteers on acute ascent to 4,340 $\mathrm{m}$ altitude [10]. In 11 high-altitude residents with chronic mountain sickness, progressive iron deficiency produced by staged venesection of $2 \mathrm{~L}$ blood also increased pulmonary artery systolic pressure, although no acute effect of iron replacement was detected. Together, these data indicate that variation in iron availability in the normal physiological range in the absence of overt anaemia can affect pulmonary vascular tone and hypoxic pulmonary hypertension, and clinical iron deficiency could exacerbate pulmonary hypertensive disease [11].

\section{IRON IN CHRONIC HEART FAILURE}

Anaemia is a powerful prognostic indicator in patients with chronic heart failure (CHF) [12-14]. A recent prospective study of $546 \mathrm{CHF}$ patients also found that iron deficiency itself, independent of the other prognostic indicators including anaemia, was associated with increased mortality [15]. In fact, several studies (table 1) have now attempted to address the potential value of parenteral iron therapy in CHF [16-20]. The results indicate that iron replacement therapy can improve haemoglobin levels, exercise capacity, functional class, quality of life, and biochemical markers of myocardial stress and inflammation. These investigations culminated in the large multicentre Ferric Carboxymaltose in Patients with Heart Failure and Iron Deficiency study, which recruited 459 patients with CHF (New York Heart Association (NYHA) class II or III) and iron deficiency, as defined by ferritin $<100 \mu \mathrm{g} \cdot \mathrm{L}^{-1}$, or 100 $299 \mu \mathrm{g} \cdot \mathrm{L}^{-1}$ if transferrin saturations were $<20 \%$, and haemoglobin between 9.5 and $13.5 \mathrm{~g} \cdot \mathrm{dL}^{-1}$ [20]. Patients were randomised (iron:placebo 2:1) to receive intravenous ferric carboxymaltose (Ferinject ${ }_{\circledR}$; Vifor Pharma UK Ltd, Bagshot Park, UK) or placebo and two primary end-points (patient self-reported global assessment and NYHA class) showed significant improvements 24 weeks after infusion. Significant differences were also observed in end-points (including quality-of-life questionnaires and exercise capacity) at other stages of the study. More importantly, improvements were seen irrespective of the presence of anaemia, and no significant difference in haemoglobin levels was observed between the treatment and placebo arms at baseline or 24 weeks later.

The data were consistent with earlier studies in rats, demonstrating the nonanaemic manifestations of iron deficiency [21]. In the presence of normal haemoglobin levels, iron deficiency was shown to impair exercise capacity and induce selective skeletal muscle changes in metabolic enzymes, which were amended by intraperitoneal injections of iron [21]. Parenteral treatment of iron-deficient anaemic subjects with iron-dextran was also reported to increase work capacity independently of

TABLE 1 Intravenous iron replacement therapy studies in left heart failure patients

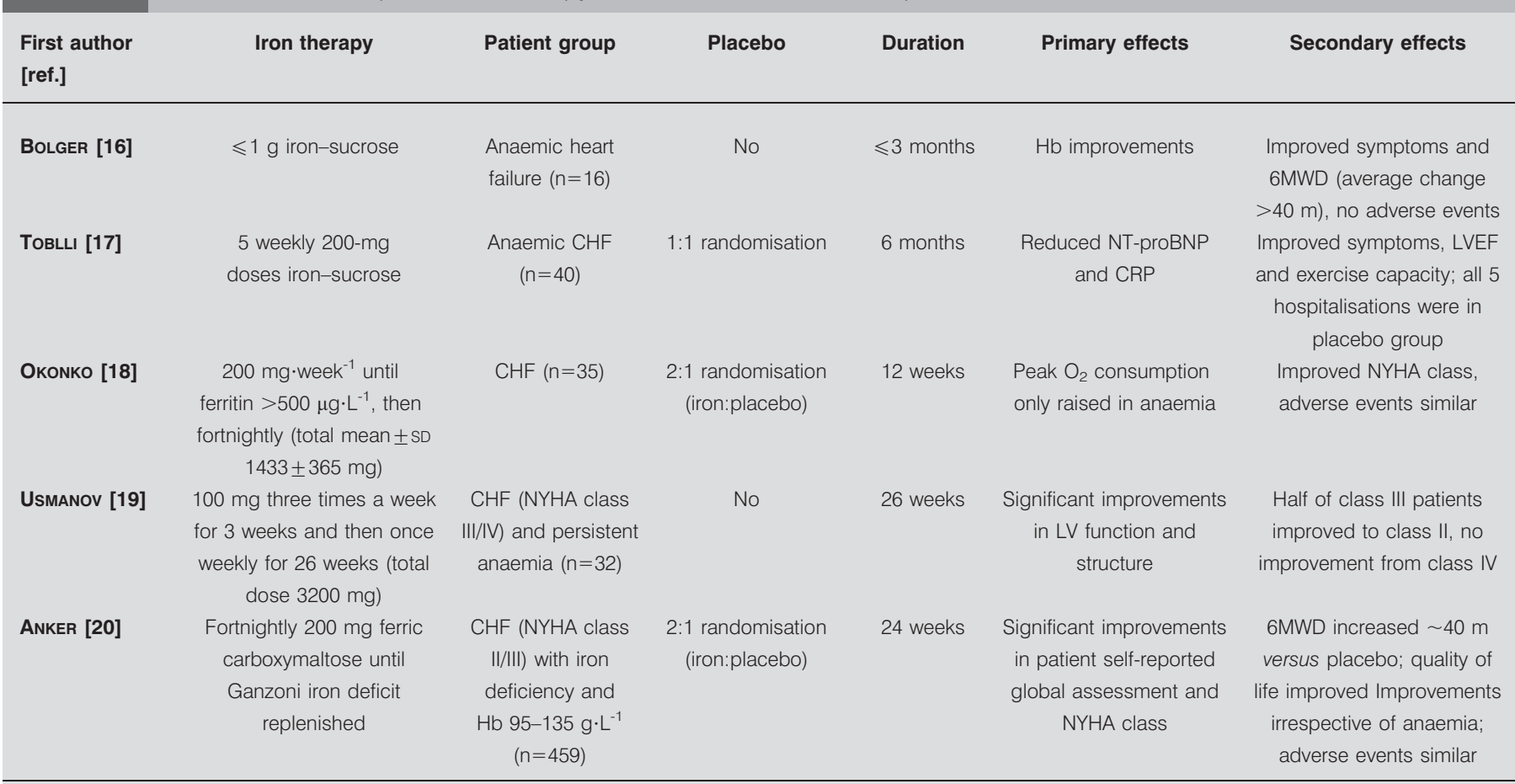

CHF: chronic heart failure; NYHA: New York Heart Association; Hb: haemoglobin; NT-proBNP: N-terminal pro-brain natriuretic peptide; CRP: C-reactive protein; LV: left ventricle; 6MWD: 6-min walk distance; LVEF: LV ejection fraction. 

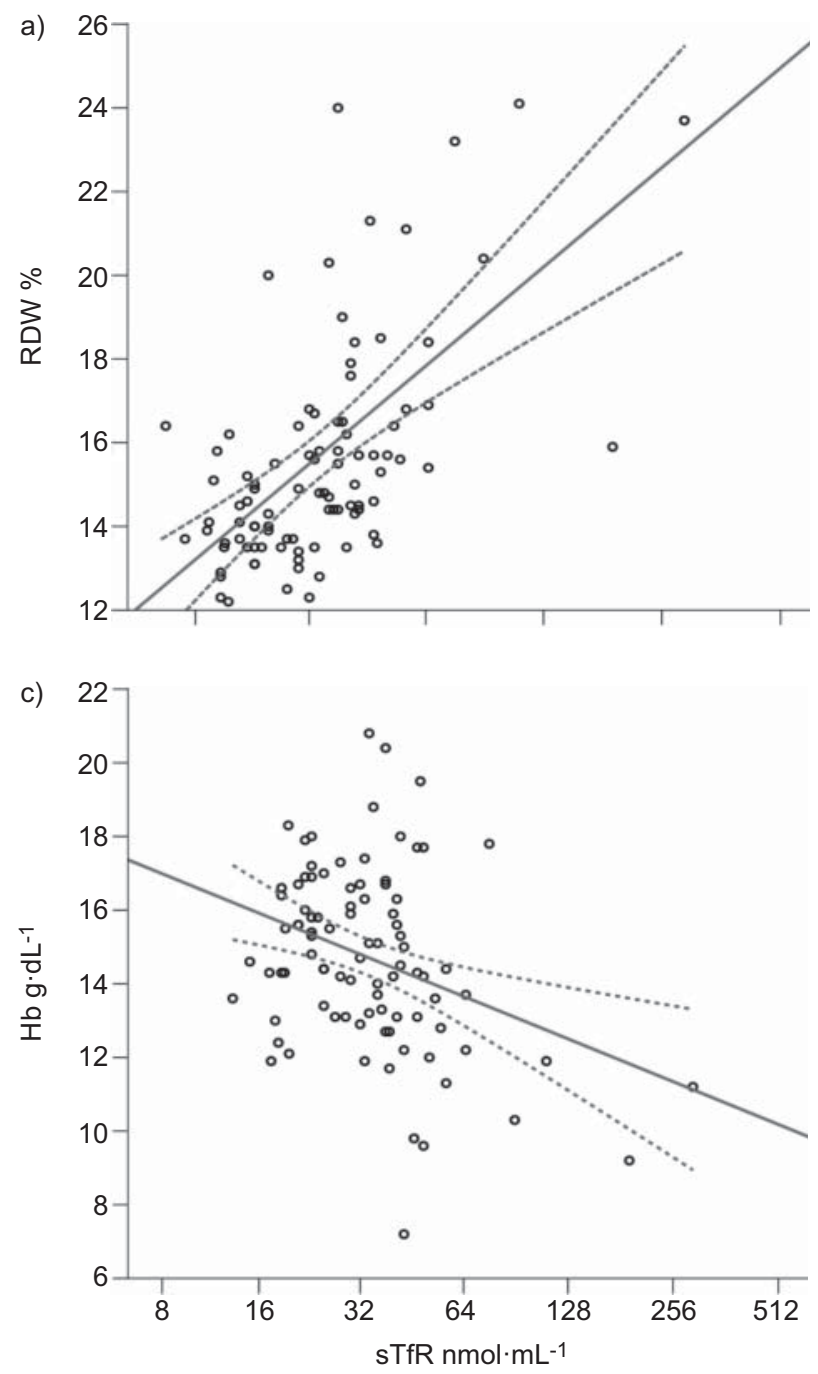

haemoglobin levels [22], but further investigations are required to determine the mechanisms underlying this phenomenon.

\section{IRON STATUS AND PROGNOSTIC BIOMARKERS IN PULMONARY HYPERTENSION}

In addition to the effects of iron on pulmonary vascular tone and the symptoms of $\mathrm{CHF}$, iron has been implicated in the pathophysiology of pulmonary hypertension through studies of prognostic biomarkers. Red cell distribution width (RDW) is a measure of the variability of red blood cell size and is used clinically to distinguish iron deficiency anaemias. RDW is predictive of cardiovascular mortality in otherwise healthy older adults [23], and its prognostic power in CHF has been linked to iron deficiency and ineffective erythropoiesis [24]. In patients with pulmonary hypertension, RDW predicted mortality, outperforming more established markers, such as Nterminal pro-brain natriuretic peptide and blood urea nitrogen measurements, in multivariable models [25].

More recently, anaemia was found to be associated with poor survival in patients with pulmonary hypertension, the prognostic significance of anaemia being independent of known predictors of mortality including age, NYHA functional

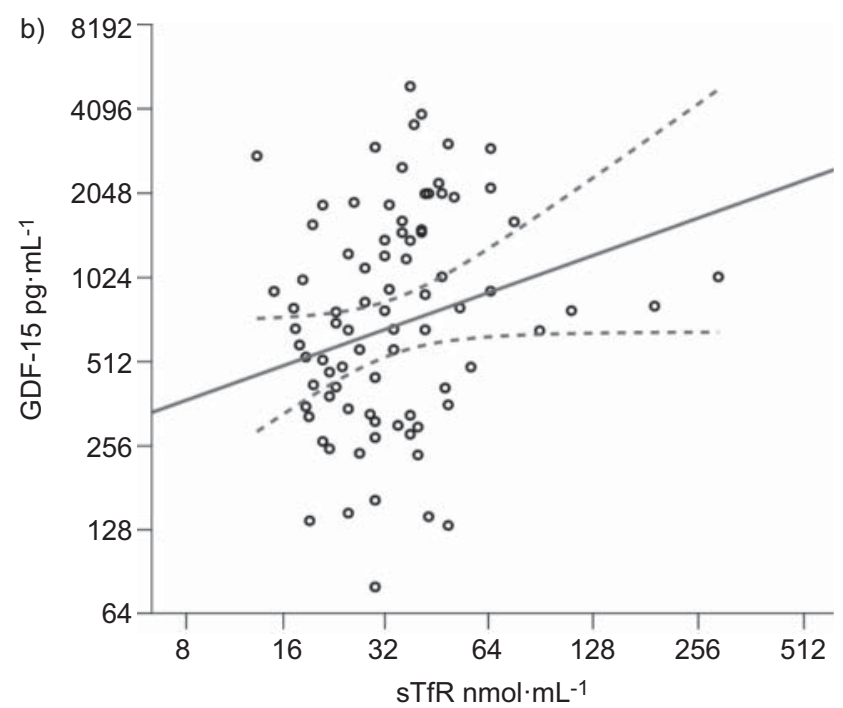

FIGURE 1. Correlation of the prognostic biomarkers a) red cell distribution width (RDW; Spearman's rank test $r=0.569, p<0.001$ ), b) growth differentiation factor (GDF)-15 ( $r=0.281, p<0.01)$ and $c)$ haemoglobin $(\mathrm{Hb} ; r=0.278, p<0.01)$ with iron status (soluble transferrin receptor; sTfR) in idiopathic pulmonary arterial hypertension patients [5].

class, grade of tricuspid regurgitation, pulmonary vascular resistance and the aetiology of pulmonary hypertension [26]. Another potential biomarker in pulmonary hypertension is growth differentiation factor (GDF)-15 [27]. Circulating GDF15 levels are raised in patients with IPAH [27] and production can be induced in several isolated cell types as well as in healthy volunteers following treatment with desferrioxamine [28]. Data from our own laboratory indicate that RDW, GDF-15 and haemoglobin levels correlate to a varying extent with iron status, as indicated by circulating levels of soluble transferrin receptor (sTfR), in patients with IPAH (fig. 1).

\section{IRON DEFICIENCY IN IPAH}

Recently, three research groups have independently examined the prevalence of iron deficiency in IPAH [3-5]. In the first of these studies, RUITER et al. [3] found iron deficiency, as defined by reduced serum iron and transferrin saturations, in 30 (43\%) out of 70 patients. Iron deficiency, irrespective of the existence of anaemia, was associated with a lower exercise capacity, as assessed by 6-min walk distance (6MWD). Interestingly, oral iron therapy was only effective at increasing ferritin levels in eight $(44 \%)$ out of 18 patients, suggesting that dietary iron uptake may be dysfunctional in these patients. In a separate 
study, Soon et al. [4] also described an association between IPAH and iron deficiency, defined primarily on the basis of low ferritin levels $\left(<10 \mu \mathrm{g} \cdot \mathrm{L}^{-1}\right)$, with normal transferrin levels. Iron deficiency was most marked in pre-menopausal females, and patients with heritable $\mathrm{PAH}(\mathrm{HPAH})$ and mutations in the bone morphogenetic protein receptor type II (BMPR2) [4].

One difficulty in assessing the iron status of individuals with chronic diseases such as IPAH is the frequent coincidence of inflammation and the potential effects this may have on iron homeostasis (see later). The presence of inflammation can confound determination of iron status, as ferritin is induced whilst serum iron and transferrin saturations are repressed [29]. STfR levels offer an alternative means of measuring iron availability that is unaffected by inflammation [30,31]. Circulating sTfR levels in the normal range reflect erythropoietic activity (i.e. the uptake of iron in the bone marrow by transferrin receptors), whereas levels are disproportionately raised in iron deficiency [31] and may be a better marker of iron deficiency in diseases such as IPAH.

RHODES et al. [5] determined circulating sTfR levels in 98 patients with IPAH and found a high prevalence (63\%) of iron deficiency (as defined by sTfR levels raised above the upper end of the normal range, $28.1 \mathrm{nmol} \cdot \mathrm{L}^{-1}$ ) without overt anaemia. Furthermore, raised STfR levels were associated with lower exercise capacity, higher World Health Organization (WHO) functional class and mortality, predicting survival independently of WHO class, 6MWD and age [5]. These data highlight the prevalence of iron deficiency in IPAH and suggest that it is clinically important, although the underlying cause is not clear. Possible reasons include reduced iron intake, chronic blood loss and impaired iron absorption. There is no reason to indicate that patients with IPAH have a diet that is deficient in iron and, although these patients are predominantly female, the differences could not be attributed to the potentially confounding effects of warfarin or targeted therapies for PAH [3-5].

Patients with IPAH exhibit significant changes in skeletal muscle [32]. One hypothesis is that the reduced exercise capacity observed in iron-deficient IPAH patients [3,5] reflects irondependent alterations in myoglobin and muscle oxygen homeostasis. Aside from haemoglobin, myoglobin is the most abundant haem-containing, and therefore iron-dependent, protein in humans [33]. This extensively studied protein has a number of key functions, acting to maintain tissue oxygen concentrations, facilitate oxygen diffusion from capillaries to mitochondria and regulate nitric oxide levels. Myoglobin scavenges nitric oxide and reactive oxygen species under oxygenated conditions and produces nitric oxide from nitrite under deoxygenated conditions $[34,35]$. Studies in human volunteers indicate that in some situations where erythropoiesis is strongly stimulated, for example at high altitude $(4,500 \mathrm{~m})$, myoglobin may represent a source of iron for haemoglobin production [36]. This effect contrasts with previously noted adaptations to chronic hypoxia; increased skeletal muscle myoglobin has been demonstrated in humans and animals living at high altitude and deep-sea diving animals [37-39]. However, myoglobin expression is not directly induced by hypoxia alone but by hypoxia in combination with exercise or other stimuli of calcium signalling in muscle [40].
Muscle myoglobin levels may also be low in patients with IPAH (A. Vonk-Noordegraaf, unpublished observations). Since myoglobin acts as an "intracellular haemoglobin", reducing oxygen tension in the cytoplasm and, therefore, facilitating further oxygen diffusion into the cell, low myoglobin levels could directly affect oxygen extraction and so exercise capacity. A similar hypothesis has been raised in $\mathrm{CHF}$, though recent data suggested exercise intolerance in these patients was not due to myoglobin deficiency [41]. At present, it is unknown whether skeletal muscle myoglobin levels are substantially affected in iron-deficient IPAH patients.

\section{REGULATION OF IRON HOMEOSTASIS IN IPAH}

The control of circulating and intracellular iron concentrations is important to enable both effective erythropoiesis and the activity of iron-dependent biochemical reactions, iron being essential for normal cellular metabolism and respiration. Iron overload is also detrimental, leading to toxicity and cell death, primarily due to formation of free radicals via the Fenton or Haber-Weiss reactions [42, 43]. Thus, iron homeostasis is tightly controlled. Around two-thirds of the body's iron is found in haemoglobin in erythrocytes, and $\sim 10 \%$ in muscle myoglobin or enzymes and cytochromes in other tissues. Under normal iron-replete conditions, the majority of the remaining iron is stored intracellularly, bound to ferritin or haemosiderin molecules, in the reticuloendothelial system and bone marrow [33]. Erythrocyte iron is effectively recycled by macrophages of the reticuloendothelial system, with cell-free haemoglobin and haem being scavenged by haptoglobin and haemopexin molecules, respectively. There is no mechanism for iron excretion and the small daily loss of iron (1-3 mg), due to sloughing of intestinal mucous cells, menstruation and other blood loss, is balanced by dietary iron absorption.

The master regulator of iron homeostasis is hepcidin, which acts to inhibit the efflux of iron into the blood from enterocytes and iron storing cells by binding to ferroportin and inducing its degradation in lysosomes [44]. Hepcidin is thought to be expressed mainly in the liver and its production is inhibited by iron deficiency and increased erythropoiesis, and induced by iron overload and inflammation (fig. 2). Chronically raised hepcidin levels cause systemic iron deficiency and underlie the anaemia of chronic disease [29]. Some patients with IPAH exhibit raised circulating hepcidin levels in the face of iron deficiency, suggesting that inhibition of dietary iron uptake by hepcidin might contribute to iron deficiency [5]. This is also consistent with the lack of an effect of oral iron therapy in a majority of IPAH patients [3].

The mechanisms of iron sensing are not well understood, but it has become apparent that bone morphogenetic protein (BMP) signalling has a critical role in controlling hepcidin expression. The BMPs are a multifunctional family of proteins that act through binding to heteromeric combinations of type 1 and 2 receptors, leading to the activation (phosphorylation) and nuclear translocation of receptor-activated SMADs (SMAD1, 5 and 8) and the common SMAD4 [45]. BMP-6 has emerged as the principal BMP regulating hepatic hepcidin expression in vivo. Iron stimulates BMP-6 expression, leading to increased hepcidin expression, whereas BMP-6 knockout mice display severe iron overload and reduced hepcidin expression [46-49]. This pathway is of particular interest in PAH as BMPR2 


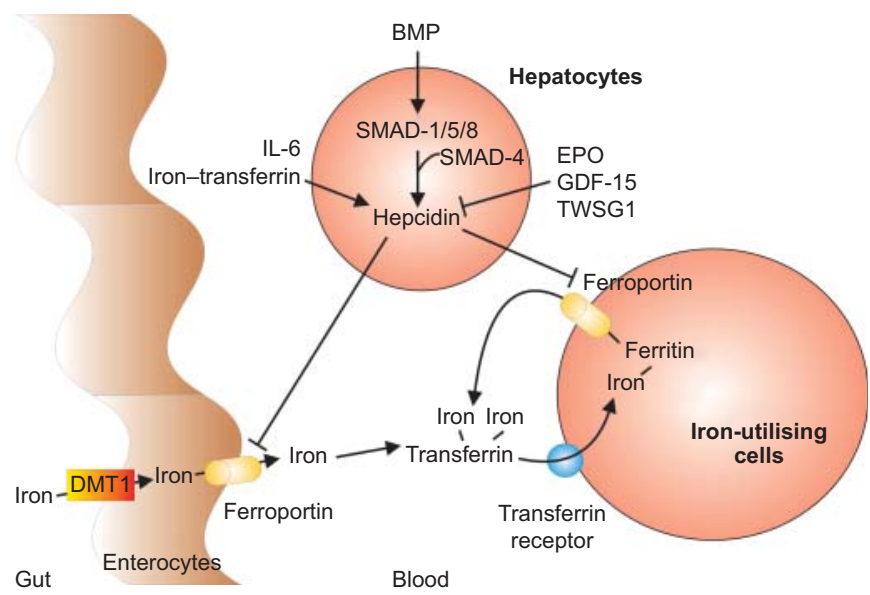

FIGURE 2. Regulation of dietary iron uptake and release from iron-utilising cells by hepcidin. Hepcidin acts to internalise ferroportin, leading to its degradation and inhibition of dietary iron uptake and release of iron from iron-utilising or -storing cells. Hepcidin is regulated by several factors, though bone morphogenetic protein (BMP) signalling through the SMAD transcription factors, which can be modulated by haemojuvelin, appears to be of particular importance. Hepcidin expression can be stimulated by inflammation (through interleukin (IL)-6) and circulating iron (irontransferrin). Erythropoiesis (and erythropoietin (EPO)) indirectly inhibits hepcidin, and circulating erythroid factors, such as growth differentiation factor (GDF)-15 and twisted gastrulation (TWSG) 1, have been proposed to directly inhibit hepcidin. Divalent metal transporter (DMT)1 is responsible for uptake of dietary iron into enterocytes.

expression is reportedly reduced in IPAH patients and loss-offunction BMPR2 mutations have been linked to $>70 \%$ of familial and $\sim 20 \%$ of idiopathic cases of PAH [50, 51]. Interestingly, the stimulation of hepcidin expression and protein production by BMP-6 in human hepatoma HepG2 cells is increased following the knockdown of BMPR2 by small interfering RNA transfection, raising the possibility that dysfunctional BMPR2 signalling may contribute to raised hepcidin levels and, therefore, iron deficiency in PAH [5].

Hepcidin is an acute-phase reactant protein [52] that is induced by interleukin (IL)-6 during inflammation [53]. IL-6 levels are known to be increased in IPAH but, as discussed previously, attempts to establish a relationship with iron status may be confounded by the effect of inflammation on indices such as serum iron, ferritin and transferrin saturations. Nonetheless, RHODES et al. [5] found no correlation between hepcidin levels and IL-6 or C-reactive protein in IPAH patients, whether or not iron status was taken into account by considering sTfR or ferritin levels. SoON et al. [4] also found that higher IL-6 levels were not accompanied by increased hepcidin in IPAH, suggesting that inflammation and IL-6 are not the principal cause of raised hepcidin and iron deficiency in these patients. Nonetheless, BMP signalling and IL- 6 may act together to regulate iron homeostasis and the inhibition of BMP signalling has been put forward as a means of targeting hepcidin production and anaemia associated with inflammation [54].

Erythropoietin is another potential regulator of hepcidin that is increased in IPAH. However, as in healthy controls, there is a negative correlation between the two that is consistent with a reduction in hepcidin production as erythropoietic demand for iron increases $[5,55]$. Iron deficiency or anaemia may also drive increases in other HIF-inducible factors, including the myeloidactivating factors stromal-derived factor- $1 \alpha$, stem cell factor and hepatocyte growth factor [55]. This might contribute to myeloproliferative processes and recruitment of pro-angiogenic progenitor (CD34+ CD133+) cells to the pulmonary vasculature in PAH patients [55]. Interestingly, myeloid abnormalities were also demonstrated in unaffected relations of $\mathrm{HPAH}$ patients, suggesting that HIF-inducible factors and myeloid abnormalities may have a role in the pathology of PAH prior to the clinical manifestation of the disease. It remains to be determined whether these processes are exacerbated by iron deficiency or anaemia in PAH. Nevertheless, iron chelation with desferrioxamine has recently been shown to increase the pro-angiogenic activity of vascular endothelial cells [56].

\section{GENETIC DETERMINANTS OF IRON STATUS}

Genetic factors are thought to make a substantial contribution to variation in iron status [57-59]. Indeed, genome-wide association studies have identified common gene variants connected with haemoglobin levels and blood cell traits indicative of altered erythropoiesis and iron regulation. These include singlenucleotide polymorphisms in the TMPRSS6 and TRF2 genes, encoding the serine protease matriptase- 2 and transferrin receptor type-2, which associate with variation in iron and haemoglobin levels and RDW [60-63]. In addition, a recent study has linked the TMPRSS6 genotype with hepcidin production and suggested that some variants may be more susceptible to an imbalance in iron homeostasis [64]. Further studies are required to investigate whether such genetic differences contribute to the dysregulation of iron homeostasis in pulmonary hypertension.

\section{IRON DEFICIENCY AS A POTENTIAL THERAPEUTIC TARGET IN IPAH}

Although iron deficiency is prevalent in IPAH and may impact on the exercise capacity, disease severity and survival of these patients, it is unclear whether this involves effects on pulmonary haemodynamics, cardiac function and/or skeletal muscle function. It will also be important to explore the safety and efficacy of therapeutic strategies designed to improve iron homeostasis in IPAH. Thus, in contrast to the negative pulmonary effects of iron deficiency, increasing pulmonary vascular tone and exacerbating hypoxia-induced pulmonary hypertension [8-10], it has recently been proposed that iron depletion may inhibit the development of right ventricular hypertrophy in pulmonary hypertension [65]. This suggestion arose from the finding that expression of the transcription factor GATA4, a major regulator of cardiac hypertrophy, was enhanced in the right ventricle of rats following pulmonary artery banding or exposure to chronic hypoxia, and was dependent on iron-catalysed protein oxidation and degradation. The expression of GATA4 has also been implicated in regulating transcription of the S100 calciumbinding protein S100A4/Mts1 [66], which is overexpressed in pulmonary vascular lesions [67], and in mediating the growth effects of serotonin and endothelin-1, which are known to be related to pulmonary vascular remodelling in PAH $[68,69]$, in pulmonary artery smooth muscle cells [70].

Studies on iron in rat models of systemic cardiovascular disease have provided inconsistent results, with protective [71] as well as detrimental effects being attributed to iron deficiency $[72,73]$. Such differences may reflect variations in iron handling between 
rat strains [71,74]. Iron loading has also been proposed as a risk factor for atherosclerosis [75]; accumulation of iron in atherosclerotic plaque macrophages being linked with oxidative stress, the release of pro-inflammatory cytokines and raised hepcidin levels, whereas low levels of hepcidin may be associated with reduced macrophage iron stores [76]. The normal pulmonary vascular bed is protected from atherosclerosis and it is unclear if inappropriately raised hepcidin levels in IPAH are associated with pulmonary vascular lesions.

There are a number of challenges to the design of therapeutic strategies for iron supplementation in IPAH. Dosing is a complex issue, as the use of the Ganzoni formula to calculate iron deficiency [77] is not applicable in a patient population such as those with IPAH, where haemoglobin levels are within the normal range. Nevertheless, the use of ferric carboxymaltose (Ferinject $\mathrm{B}$ ) could potentially enable a single dose of $\leqslant 1 \mathrm{~g}$ to be administered by infusion to individuals with a body weight of $>35 \mathrm{~kg}$. Half of this amount would be expected to replenish the iron stores of an individual with a body weight of $>35 \mathrm{~kg}$, the remainder being sufficient to increase haemoglobin levels by up to $\sim 3 \mathrm{~g} \cdot \mathrm{dL}^{-1}[77]$.

Another important issue is the selection of appropriate endpoints to evaluate the effects of intravenous iron supplementation, in particular, novel end-points that require relatively few patients [78]. Trials of new therapies in PAH have traditionally assessed effects on exercise capacity by measuring $6 \mathrm{MWD}$, but in the case of iron supplementation, direct measurements of skeletal muscle strength and endurance, muscle histochemistry and oxygen utilisation are also warranted. The apparent impact of iron status on the regulation of pulmonary vascular tone [8-10] and relatively low variability in measurements of pulmonary vascular resistance, as determined by cardiac catheterisation, make this an attractive end-point for investigating the possible pulmonary haemodynamic benefits of iron therapy. Other potentially useful end-points include cardiopulmonary exercise testing and exercise endurance, which may provide further insight into how iron availability affects functional capacity [79], and cardiac magnetic resonance imaging, which, like pulmonary vascular resistance, exhibits relatively little variation and, hence, higher power to detect structural and functional differences of the ventricles in small patient populations [80, 81]. Two parallel studies from our centre (Hammersmith Hospital, London, UK) and others in the UK and Amsterdam (the Netherlands) have been established to examine the multifaceted aspects of the response to intravenous iron replacement in $\mathrm{PAH}$, incorporating these end-points in addition to safety measures.

\section{SUMMARY AND CONCLUSIONS}

Iron status influences several important aspects of physiology that are relevant to pulmonary hypertension. The prevalence and prognostic power of iron deficiency in IPAH patients indicates that it is a potential therapeutic target. Dietary iron absorption may be repressed in these patients, and clinical studies are underway to explore the safety and possible benefit of parenteral iron treatment in IPAH.

\section{SUPPORT STATEMENT}

This work was supported by grants from the British Heart Foundation (London, UK), Medical Research Council (London) and EU PULMO TENSION project.

\section{STATEMENT OF INTEREST}

None declared.

\section{ACKNOWLEDGEMENTS}

We would like to thank M. Pritzker (Division of Cardiology, Department of Medicine, University of Minnesota, Minneapolis, MN, USA) for his insights on the topic of iron deficiency in cardiovascular diseases.

\section{REFERENCES}

1 Archer SL, Weir EK, Wilkins MR. Basic science of pulmonary arterial hypertension for clinicians: new concepts and experimental therapies. Circulation 2010; 121: 2045-2066.

2 Simonneau G, Robbins IM, Beghetti M, et al. Updated clinical classification of pulmonary hypertension. J Am Coll Cardiol 2009; 54: S43-S54.

3 Ruiter G, Lankhorst S, Boonstra A, et al. Iron deficiency is common in idiopathic pulmonary arterial hypertension. Eur Respir J 2011; 37: 1386-1391.

4 Soon E, Treacy CM, Toshner MR, et al. Unexplained iron deficiency in idiopathic and heritable pulmonary arterial hypertension. Thorax 2011; 66: 326-332.

5 Rhodes CJ, Howard LS, Busbridge M, et al. Iron deficiency and raised hepcidin in idiopathic pulmonary arterial hypertension: clinical prevalence, outcomes and mechanistic insights. J Am Coll Cardiol 2011; 58: 300-309.

6 Ivan M, Kondo K, Yang H, et al. HIF $\alpha$ targeted for VHL-mediated destruction by proline hydroxylation: implications for $\mathrm{O}_{2}$ sensing. Science 2001; 292: 464-468.

7 Jaakkola P, Mole DR, Tian YM, et al. Targeting of HIF- $\alpha$ to the von Hippel-Lindau ubiquitylation complex by $\mathrm{O}_{2}$-regulated prolyl hydroxylation. Science 2001; 292: 468-472.

8 Balanos GM, Dorrington KL, Robbins PA. Desferrioxamine elevates pulmonary vascular resistance in humans: potential for involvement of HIF-1. J Appl Physiol 2002; 92: 2501-2507.

9 Smith TG, Balanos GM, Croft QP, et al. The increase in pulmonary arterial pressure caused by hypoxia depends on iron status. J Physiol 2008; 586: 5999-6005.

10 Smith TG, Talbot NP, Privat C, et al. Effects of iron supplementation and depletion on hypoxic pulmonary hypertension: two randomized controlled trials. JAMA 2009; 302: 1444-1450.

11 Joyner MJ, Johnson BD. Iron lung? New ideas about hypoxic pulmonary vasoconstriction. J Physiol 2008; 586: 5837-5838.

12 Al-Ahmad A, Rand WM, Manjunath G, et al. Reduced kidney function and anemia as risk factors for mortality in patients with left ventricular dysfunction. J Am Coll Cardiol 2001; 38: 955-962.

13 Horwich TB, Fonarow GC, Hamilton MA, et al. Anaemia is associated with worse symptoms, greater impairment in functional capacity and a significant increase in mortality in patients with advanced heart failure. J Am Coll Cardiol 2002; 39: 1780-1786.

14 Mozaffarian D, Nye R, Levy WC. Anaemia predicts mortality in severe heart failure: the prospective randomized amlodipine survival evaluation (PRAISE). J Am Coll Cardiol 2003; 41: 1933-1939.

15 Jankowska EA, Rozentryt P, Witkowska A, et al. Iron deficiency: an ominous sign in patients with systolic chronic heart failure. Eur Heart J 2010; 31: 1872-1880.

16 Bolger AP, Bartlett FR, Penston HS, et al. Intravenous iron alone for the treatment of anaemia in patients with chronic heart failure. J Am Coll Cardiol 2006; 48: 1225-1227.

17 Toblli JE, Lombrana A, Duarte P, et al. Intravenous iron reduces NT-pro-brain natriuretic peptide in anemic patients with chronic heart failure and renal insufficiency. J Am Coll Cardiol 2007; 50: 1657-1665.

18 Okonko DO, Grzeslo A, Witkowski T, et al. Effect of intravenous iron sucrose on exercise tolerance in anemic and nonanemic patients with symptomatic chronic heart failure and iron deficiency: 
FERRIC-HF: a randomized, controlled, observer-blinded trial. J Am Coll Cardiol 2008; 51: 103-112.

19 Usmanov RI, Zueva EB, Silverberg DS, et al. Intravenous iron without erythropoietin for the treatment of iron deficiency anemia in patients with moderate to severe congestive heart failure and chronic kidney insufficiency. J Nephrol 2008; 21: 236-242.

20 Anker SD, Comin CJ, Filippatos G, et al. Ferric carboxymaltose in patients with heart failure and iron deficiency. N Engl J Med 2009; 361: 2436-2448.

21 Finch CA, Miller LR, Inamdar AR, et al. Iron deficiency in the rat. Physiological and biochemical studies of muscle dysfunction. J Clin Invest 1976; 58: 447-453.

22 Ohira Y, Edgerton VR, Gardner GW, et al. Work capacity, heart rate and blood lactate responses to iron treatment. $\mathrm{Br} J$ Haematol 1979; 41: 365-372.

23 Patel KV, Semba RD, Ferrucci L, et al. Red cell distribution width and mortality in older adults: a meta-analysis. J Gerontol A Biol Sci Med Sci 2010; 65: 258-265.

24 Forhecz Z, Gombos T, Borgulya G, et al. Red cell distribution width in heart failure: prediction of clinical events and relationship with markers of ineffective erythropoiesis, inflammation, renal function, and nutritional state. Am Heart J 2009; 158: 659-666.

25 Hampole CV, Mehrotra AK, Thenappan T, et al. Usefulness of red cell distribution width as a prognostic marker in pulmonary hypertension. Am J Cardiol 2009; 104: 868-872.

26 Krasuski RA, Hart SA, Smith B, et al. Association of anaemia and long-term survival in patients with pulmonary hypertension. Int $J$ Cardiol 2011; 150: 291-295.

27 Nickel N, Kempf T, Tapken H, et al. Growth differentiation factor15 in idiopathic pulmonary arterial hypertension. Am J Respir Crit Care Med 2008; 178: 534-541.

28 Lakhal S, Talbot NP, Crosby A, et al. Regulation of growth differentiation factor 15 expression by intracellular iron. Blood 2009; 113: 1555-1563.

29 Weiss G, Goodnough LT. Anaemia of chronic disease. N Engl J Med 2005; 352: 1011-1023.

30 Cook JD, Dassenko S, Skikne BS. Serum transferrin receptor as an index of iron absorption. Br J Haematol 1990; 75: 603-609.

31 Huebers HA, Beguin Y, Pootrakul P, et al. Intact transferrin receptors in human plasma and their relation to erythropoiesis. Blood 1990; 75: 102-107.

32 Mainguy V, Maltais F, Saey D, et al. Peripheral muscle dysfunction in idiopathic pulmonary arterial hypertension. Thorax 2010; 65: 113-117.

33 Finch CA, Deubelbeiss K, Cook JD, et al. Ferrokinetics in man Medicine (Baltimore) 1970; 49: 17-53.

34 Brunori M. Myoglobin strikes back. Protein Sci 2010; 19: 195-201.

35 Flogel U, Fago A, Rassaf T. Keeping the heart in balance: the functional interactions of myoglobin with nitrogen oxides. J Exp Biol 2010; 213: 2726-2733.

36 Robach P, Cairo G, Gelfi C, et al. Strong iron demand during hypoxia-induced erythropoiesis is associated with down-regulation of iron-related proteins and myoglobin in human skeletal muscle. Blood 2007; 109: 4724-4731.

37 Reynafarje B. Myoglobin content and enzymatic activity of muscle and altitude adaptation. J Appl Physiol 1962; 17: 301-305.

38 Kooyman GL, Ponganis PJ. The physiological basis of diving to depth: birds and mammals. Annu Rev Physiol 1998; 60: 19-32.

39 Kanatous SB, Garry DJ. Gene deletional strategies reveal novel physiological roles for myoglobin in striated muscle. Respir Physiol Neurobiol 2006; 151: 151-158.

40 Kanatous SB, Mammen PP, Rosenberg PB, et al. Hypoxia reprograms calcium signaling and regulates myoglobin expression. Am J Physiol Cell Physiol 2009; 296: C393-C402.

41 Bekedam MA, van Beek-Harmsen BJ, van Mechelen W, et al. Myoglobin concentration in skeletal muscle fibers of chronic heart failure patients. J Appl Physiol 2009; 107: 1138-1143.
42 Halliwell B, Gutteridge JM. Role of free radicals and catalytic metal ions in human disease: an overview. Methods Enzymol 1990; 186: 1-85.

43 Papanikolaou G, Pantopoulos K. Iron metabolism and toxicity. Toxicol Appl Pharmacol 2005; 202: 199-211.

44 Nemeth E, Ganz T. The role of hepcidin in iron metabolism. Acta Haematol 2009; 122: 78-86.

45 Goumans MJ, Liu Z, Ten Dijke P. TGF- $\beta$ signaling in vascular biology and dysfunction. Cell Res 2009; 19: 116-127.

46 Wang $\mathrm{RH}, \mathrm{Li} \mathrm{C}, \mathrm{Xu} \mathrm{X}$, et al. A role of SMAD4 in iron metabolism through the positive regulation of hepcidin expression. Cell Metab 2005; 2: 399-409.

47 Andriopoulos B Jr, Corradini E, Xia Y, et al. BMP6 is a key endogenous regulator of hepcidin expression and iron metabolism. Nat Genet 2009; 41: 482-487.

48 Meynard D, Kautz L, Darnaud V, et al. Lack of the bone morphogenetic protein BMP6 induces massive iron overload. Nat Genet 2009; 41: 478-481.

49 Niederkofler V, Salie R, Arber S. Hemojuvelin is essential for dietary iron sensing, and its mutation leads to severe iron overload. J Clin Invest 2005; 115: 2180-2186.

50 Atkinson C, Stewart S, Upton PD, et al. Primary pulmonary hypertension is associated with reduced pulmonary vascular expression of type II bone morphogenetic protein receptor. Circulation 2002; 105: 1672-1678.

51 Machado RD, Eickelberg O, Elliott CG, et al. Genetics and genomics of pulmonary arterial hypertension. J Am Coll Cardiol 2009; 54: S32-S42.

52 Nemeth E, Valore EV, Territo M, et al. Hepcidin, a putative mediator of anaemia of inflammation, is a type II acute-phase protein. Blood 2003; 101: 2461-2463.

53 Nemeth E, Rivera S, Gabayan V, et al. IL-6 mediates hypoferremia of inflammation by inducing the synthesis of the iron regulatory hormone hepcidin. J Clin Invest 2004; 113: 1271-1276.

54 Steinbicker AU, Sachidanandan C, Vonner AJ, et al. Inhibition of bone morphogenetic protein signaling attenuates anaemia associated with inflammation. Blood 2011; 117: 4915-4923.

55 Farha S, Asosingh $\mathrm{K}, \mathrm{Xu} \mathrm{W}$, et al. Hypoxia-inducible factors in human pulmonary arterial hypertension: a link to the intrinsic myeloid abnormalities. Blood 2011; 117: 3485-3493.

56 Ikeda Y, Tajima S, Yoshida S, et al. Deferoxamine promotes angiogenesis via the activation of vascular endothelial cell function. Atherosclerosis 2011; 215: 339-347.

57 Benyamin B, McRae AF, Zhu G, et al. Variants in TF and HFE explain approximately $40 \%$ of genetic variation in serumtransferrin levels. Am J Hum Genet 2009; 84: 60-65.

58 Njajou OT, Alizadeh BZ, Aulchenko Y, et al. Heritability of serum iron, ferritin and transferrin saturation in a genetically isolated population, the Erasmus Rucphen Family (ERF) Study. Hum Hered 2006; 61: 222-228.

59 Whitfield JB, Cullen LM, Jazwinska EC, et al. Effects of HFE C282Y and H63D polymorphisms and polygenic background on iron stores in a large community sample of twins. Am J Hum Genet 2000; 66: 1246-1258.

60 Benyamin B, Ferreira MA, Willemsen G, et al. Common variants in TMPRSS6 are associated with iron status and erythrocyte volume. Nat Genet 2009; 41: 1173-1175.

61 Chambers JC, Zhang W, Li Y, et al. Genome-wide association study identifies variants in TMPRSS6 associated with hemoglobin levels. Nat Genet 2009; 41: 1170-1172.

62 Tanaka T, Roy CN, Yao W, et al. A genome-wide association analysis of serum iron concentrations. Blood 2010; 115: 94-96.

63 Soranzo N, Spector TD, Mangino M, et al. A genome-wide metaanalysis identifies 22 loci associated with eight hematological parameters in the HaemGen consortium. Nat Genet 2009; 41: $1182-1190$. 
64 Pichler I, Minelli C, Sanna S, et al. Identification of a common variant in the TFR2 gene implicated in the physiological regulation of serum iron levels. Hum Mol Genet 2011; 20: 1232-1240.

65 Park AM, Wong CM, Jelinkova L, et al. Pulmonary hypertensioninduced GATA4 activation in the right ventricle. Hypertension 2010; 56: 1145-1151.

66 Lawrie A, Spiekerkoetter E, Martinez EC, et al. Interdependent serotonin transporter and receptor pathways regulate S100A4/ Mts1, a gene associated with pulmonary vascular disease. Circ Res 2005; 97: 227-235

67 Greenway S, van Suylen RJ, Du Marchie SG, et al. S100A4/Mts1 produces murine pulmonary artery changes resembling plexogenic arteriopathy and is increased in human plexogenic arteriopathy. Am J Pathol 2004; 164: 253-262.

68 Eddahibi S, Humbert M, Fadel E, et al. Serotonin transporter overexpression is responsible for pulmonary artery smooth muscle hyperplasia in primary pulmonary hypertension. J Clin Invest 2001; 108: 1141-1150.

69 Davie $\mathrm{N}$, Haleen $\mathrm{SJ}$, Upton $\mathrm{PD}$, et al. $\mathrm{ET}_{\mathrm{A}}$ and $\mathrm{ET}_{\mathrm{B}}$ receptors modulate the proliferation of human pulmonary artery smooth muscle cells. Am J Respir Crit Care Med 2002; 165: 398-405.

70 Suzuki YJ, Nagase H, Wong CM, et al. Regulation of Bcl-xL expression in lung vascular smooth muscle. Am J Respir Cell Mol Biol 2007; 36: 678-687.

71 Naito Y, Hirotani S, Sawada H, et al. Dietary iron restriction prevents hypertensive cardiovascular remodeling in Dahl saltsensitive rats. Hypertension 2011; 57: 497-504.

72 Dong F, Zhang X, Culver B, et al. Dietary iron deficiency induces ventricular dilation, mitochondrial ultrastructural aberrations and cytochrome c release: involvement of nitric oxide synthase and protein tyrosine nitration. Clin Sci (Lond) 2005; 109: 277-286.

73 Naito $Y$, Tsujino T, Matsumoto M, et al. Adaptive response of the heart to long-term anaemia induced by iron deficiency. Am J Physiol Heart Circ Physiol 2009; 296: H585-H593.

74 Naito $\mathrm{Y}$, Tsujino T, Fujimori $\mathrm{Y}$, et al. Impaired expression of duodenal iron transporters in Dahl salt-sensitive heart failure rats. J Hypertens 2011; 29: 741-748.

75 Sullivan JL. Macrophage iron, hepcidin, and atherosclerotic plaque stability. Exp Biol Med (Maywood) 2007; 232: 1014-1020.

76 Valenti L, Dongiovanni P, Motta BM, et al. Serum hepcidin and macrophage iron correlate with MCP-1 release and vascular damage in patients with metabolic syndrome alterations. Arterioscler Thromb Vasc Biol 2011; 31: 683-690.

77 Ganzoni AM. [Intravenous iron-dextran. therapeutic and experimental possibilities]. Schweiz Med Wochenschr 1970; 100: 301-303.

78 McLaughlin VV, Badesch DB, Delcroix M, et al. End points and clinical trial design in pulmonary arterial hypertension. J Am Coll Cardiol 2009; 54: S97-S107.

79 Arena R, Lavie CJ, Milani RV, et al. Cardiopulmonary exercise testing in patients with pulmonary arterial hypertension: an evidence-based review. J Heart Lung Transplant 2010; 29: 159-173.

80 Wilkins MR, Ali O, Bradlow W, et al. Simvastatin as a treatment for pulmonary hypertension trial. Am J Respir Crit Care Med 2010; 181: 1106-1113.

81 Wilkins MR, Paul GA, Strange JW, et al. Sildenafil versus Endothelin Receptor Antagonist for Pulmonary Hypertension (SERAPH) study. Am J Respir Crit Care Med 2005; 171: 1292-1297. 